
NBSIR 79-1752

ON CHARACTERIZING MEASURING MACHINE GEOMETRY

R. J. Hocken

B. R. Borchardt

National Engineering Laboratory

National Bureau of Standards

Washington, D.C. 20234

Final

May 1979

Issued June 1979

U.S. DEPARTMENT OF COMMERCE, Juanita M. Kreps, Secretary Jordan J. Baruch, Assistant Secretary for Science and Technology NATIONAL BUREAU OF STANDARDS, Ernest Ambler, Director 



\title{
ON CHARACTERIZING MEASURING MACHINE GEOMETRY
}

R. J. Hocken and B. R. Borchardt

\begin{abstract}
We present a simple method for removing axis nonorthogonality and checking for length dependent scale errors in two-dimensional measurements. Use of this method requires that a two-dimensional master gage (ball or grid plate, for example) be measured in two positions which differ by a rotation of the plate $90^{\circ}$ with respect to the measuring machine axes. The method is similar to that proposed by Reeve [1] but requires only linear least squares fitting on a small computer.
\end{abstract}

\section{INTRODUCTION}

Typically two-dimensional standards consist of a plate with either a grid of lines deposited on the plate or an array of spheres attached to the plate. The goal of a two-dimensional measurement is to obtain the array of coordinates of either the line intersections or the ball centers. This measurement is usually done on a coordinate measuring machine where either the plate, some locating device (microscope or LVDT probe), or a combination of the two, both gage and indicator, is moved. The coordinates are read from scales attached to the axes of motion.

In a perfect system this process gives the true coordinates, but in practice the motions are never truly rectilinear, the scales on the two axes are not identical, and the axes of motion are not orthogonal. The purpose 
of this paper is to describe a simple technique for checking for scale errors and nonorthogonality errors and removing such systematics from the measured coordinates. In this treatment it is assumed that the motions ( $x$ and $y$ ) are linear; thus straightness errors and errors due to yaw are assumed zero. [2] This measurement proceeds as follows. The plate is placed on the machine table and oriented so that its axes are aligned, as well as possible, with the machine axes. The coordinates are measured and normalized so that the specified plate origin has coordinates $(0,0)$. The plate is then rotated $90^{\circ}$, either clockwise or counterclockwise, and the coordinates remeasured. (This rotation must be within about $10 \mathrm{sec}$ of $90^{\circ}$ for the algorithm to work. Ten seconds is the equivalent of 0.0005 inch in 10 inches of travel, a figure well within the capability of any good measuring machine.) Again, the results are normalized so the plate origin has coordinates $(0,0)$. The two sets of coordinates are inputs to a linear least squares fit which estimates the nonorthogonality, the scale error, the difference between the actual rotation and $90^{\circ}$, and the average $x$ and $y$ offsets between the two sets of coordinates. From these results the nonorthogonality can be removed and the scale differences either averaged or removed, if there is some pressing reason to trust one scale over the other. (For instance, one might use a laser interferometer for one of the scales and the machine lead screw for the other.)

\section{CALCULATIONS}

Suppose the gage points on the plate can be specified by a set of vectors $\left(\underline{x}_{1}\right)_{N}$ which are the "true" coordinates. Then call the measured 
set of $\mathrm{N}$ vectors in the first position (aligned with the machine axes) $\left(\underline{x}_{1 i}\right)_{N}$. The first set of measured vectors are related to the true vectors by a matrix transformation, $\stackrel{A}{=}$ That is

$$
\underline{x}_{1 i}^{\prime}=\underline{\underline{A}} \underline{x}_{i} ; i=1, N^{-}
$$

where $\underline{A}$ is a matrix which describes the machine geometry. We call $\underline{\underline{A}}$ the machine metric. For a two-dimensional measuring machine, there are several possible and equally sensible choices for $\stackrel{A}{=}$. One choice is,

$$
\stackrel{A}{\underline{A}}^{p}=\left(\begin{array}{cc}
1 & -\alpha \\
0 & 1
\end{array}\right) \text {. }
$$

which describes a machine with scales which are equal but in which the axes are nonorthogonal by an amount $\alpha . \quad(\alpha$ is in radians and is assumed not to be more than a few microradians). This is the metric chosen by Reeve [1] in his original paper on "multiple redundancy", though he does not use the same language to express his results. The machine metric in (2) is written so that the $\mathrm{x}$ axes of the gage and machine are aligned and the $y$ axis of the machine is at an angle $90^{\circ}-\alpha$. This choice is arbitrary. A slightly more complicated metric one might sensibly choose is:

$$
\stackrel{A}{=}=\left(\begin{array}{cc}
1+\gamma & -\alpha \\
0 & 1
\end{array}\right)
$$

Here $\gamma$ is a small error term that is included to take into account the fact that the scale for the $x$ axis may be different than that for the $y$ and that one trusts the y scale more. An equivalent representation, trusting the $\mathrm{x}$ scale, would be

$$
\stackrel{\mathrm{A}}{\Rightarrow \mathrm{y}}=\left(\begin{array}{cc}
1 & -\alpha \\
0 & 1-\gamma
\end{array}\right)
$$


Elther of these forms can be built into the model described. Suppose, however, one believes the scales are different, by an amount $\gamma$, but one has no idea which scale should be trusted most. In this case one should choose a matrix that has symetry in the scale error. A reasonable choice 1s:

$$
\stackrel{A}{=}=\left(\begin{array}{cc}
i+\frac{\gamma}{2} & -\alpha \\
0 & 1-\frac{\gamma}{2}
\end{array}\right)
$$

It is shown in Appendix B, that all three of these forms, eq. 3, 4, and 5, yield identical relationships between the coordinates measured in positions 1 and 2, though not identical "best" values for the coordinates. The reason for this is simply that the numbers themselves cannot ever contain information about the true choice of scale since this is arbitrary and decided by law rather than nature. Thus, only the differences between scales may be ascertained and which one is to be termed "correct" is entirely the decision of the metrologist. Since the three more general forms for the machine metric, eqs. 3,4 , and 5 , yield the same observational equations, we can work equally well with only one of them.

Beginning then with $\mathrm{A}_{\mathrm{x}}$, we have, from equation 1 , the set of vectors (coordinates) measured in the first position. They are:

$$
\underline{x}_{I i}^{\prime}=A_{x} \underline{x}_{i}, \quad i=1, N
$$

The set of vectors measured in the second position is given by

$$
\underline{x}_{12}^{\prime}=\stackrel{A}{=} \stackrel{\underline{\underline{R}}}{=} \underline{X}_{i}, \quad 1=1, \mathrm{~N}
$$

where $\underline{B}$ is the finite rotation matrix,

where $\theta \simeq \frac{\pi}{2}$.

$$
\underline{\underline{B}}=\left(\begin{array}{cc}
\cos \theta & \sin \theta \\
-\sin \theta & \cos \theta
\end{array}\right)
$$


The order of $\underline{\underline{A}}$ and $\underline{\underline{B}}$ is important, because $\underline{\underline{A}}$ and $\underline{\underline{B}}$ do not commute

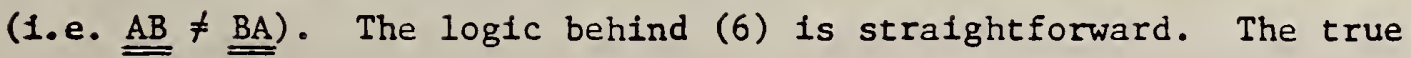
coordinates after rotation are:

$$
\underline{X}_{i B}=B \underline{X}_{i}, \quad i=1, N
$$

and when these coordinates are measured on the machine the numbers obtained are:

$$
\underline{X}_{2 i}^{\prime}=\stackrel{A}{=} \underline{X}_{i B}=\stackrel{\Delta}{=} \underline{B} \stackrel{B}{=} \underline{x}_{i}, \quad i=1, N
$$

Equations ( 1 ) and (6) may be combined to yield

$$
\underline{X}_{1 i}^{\prime}=\stackrel{A}{=} \underline{B}^{-1} \stackrel{A^{-1}}{=} \underline{x}_{2 i}^{\prime} \quad i=\cdot 1, N
$$

which is the basic observational equation. Here the data, measured coordinates in the two positions, are related by an equation which involves the machine parameters, $\alpha$ and $\gamma$, and the rotation angle $\theta$.

Equation (10) would be exactly true in the absence of error. In a measuring machine, there are, however, many errors and equation (10) is only true on the average. Also, because of the way we usually make measurements, there is probably some linear offset, independent of the machine metric, between the origins in positions 1 and 2 . The normalization procedure commonly used, that of subtracting the readings at the reference coordinate, systematically biases all measurements with the error in that one reference point measurement. This bias can be assessed by including in equation (10) an offset vector $\underline{\varepsilon}$, which is assumed small, so that

$$
\underline{x}_{1 i}=\stackrel{A}{\Rightarrow} \stackrel{B^{-1}}{=} \stackrel{A}{=}{ }_{-2}^{-1}+\underline{\varepsilon}, \quad i=1, N
$$

It is easy to show that since $\underline{\varepsilon}$ is infinitesimal, $\underline{\underline{A}} \underline{\varepsilon}=\underline{\varepsilon}$, so that its introduction at what appears to be the last minute is mathematically sound. 
We now simplify equation (11) by noting that the fintte rotation matrix $\underline{\underline{B}}(\theta)$, where $\theta=\pi / 2+\beta$, reduces to an "infinitesimal" type of matrix. That is

$$
\underline{\underline{B}}=\left(\begin{array}{ccc}
\left.\cos \frac{\pi}{2}+\beta\right) & \sin \left(\frac{\pi}{2}+\beta\right) \\
-\sin \left(\frac{\pi}{2}+\beta\right) & \cos \left(\frac{\pi}{2}+\beta\right)
\end{array}\right) \approx\left(\begin{array}{cc}
-\beta & 1 \\
-1 & -\beta
\end{array}\right)
$$

if one neglects terms in $\beta^{2}$. Also, to the same order, the inverse of $\underline{B}$ is

$$
\underline{\underline{B}}^{-1}=\left(\begin{array}{cc}
-B & -1 \\
1 & -\beta
\end{array}\right) \text {. }
$$

and the inverse of $\stackrel{A}{=}$ is

$$
\stackrel{\mathrm{A}^{-1}}{=\mathrm{x}}=\left(\begin{array}{cc}
1-\gamma & \alpha \\
0 & 1
\end{array}\right)
$$

With these first order approximations, the observational equations become:

$$
\mathrm{X}_{1 i}^{\prime}=-(\beta+\alpha) \quad \mathrm{X}_{2 i}^{\prime}-(1-\gamma) \mathrm{Y}_{2 i}^{\prime}+\varepsilon_{\mathrm{x}}
$$

and

$$
Y_{1 i}^{\prime}=(1-\gamma) X_{2 i}^{\prime}+(\alpha-\beta) Y_{2 i}^{\prime}+\varepsilon_{y}
$$

where we have performed the matrix multiplications indicated in equation (11). (We emphasize here that equation (15) is exactly the same for any of the three choices of $\stackrel{A}{=}$ equations (3), (4), and (5), mentioned previously.)

To obtain a best value for the parameters $\left(\alpha, \beta, \gamma, \varepsilon_{x} ; \varepsilon_{y}\right)$ we must choose them such that, on the average, equations (15) are satisfied. To do this, we introduce a modified form of the traditional chi-squared which we define as follows:

$$
X^{2}=\frac{1}{2 N-5} \sum_{i=1, N}\left(Y_{1 i}^{\prime}-X_{1 i}^{\prime}(\text { calc })\right)^{2}+\left(Y_{11}^{\prime}-Y_{11}^{\prime}(\text { calc })\right)^{2}
$$


where $X_{1 i}^{\prime}(c a l c)$ and $Y_{1 I}^{\prime}$ (calc) represent the right hand sides of equations (15a) and (15b), respectively. A best value for the parameters will occur when the quantity chi-squared is a minimum, and furthermore, chi-squared at this minimum is just the rms standard deviation in the coordinates. (We assume here that the random errors in the $x$ and $y$ measurements are independent with mean 0 and variance $\sigma^{2}$ )

We obtain the equations for the minimum in chi-squared by partial differentiation of equation (16) with respect to each of the five parameters, setting these derivatives equal to zero. A resulting systen of linear equations is:

$$
\underline{D} \underline{P}=\underline{C} \text {, }
$$

where $\underline{D}$ is a $5 \times 5$ matrix and $\underline{P}$ and $\underline{C}$ are column vectors. Let us denote the sums which form the matrix elements of $D$ by dropping the $i$ subscript, the prime and the summation sign.

Then:

$$
\underline{D}=\left(\begin{array}{ccccc}
0 & 2 X_{2} Y_{2} & Y_{2}^{2}+X_{2}^{2} & -Y_{2} & -X_{2} \\
X_{2}^{2} & X_{2}^{2} & Y_{2} X_{2} & X_{2} & -Y_{2} \\
-Y_{2}^{2} & Y_{2}^{2} & Y_{2} X_{2} & -Y_{2} & -X_{2} \\
X_{2} & X^{2} & Y_{2} & -N & 0 \\
-Y_{2} & Y_{2} & X_{2} & 0 & -N
\end{array}\right) .
$$

where, for example, $x_{2}^{2}=\sum_{i=1}^{N} X_{2 i}^{\prime}{ }^{2}$ and $X_{2} Y_{2}=-\sum_{i=1}^{N} X_{2 i}^{\prime} Y_{2 i}^{\prime}$. 
Similarly,

and

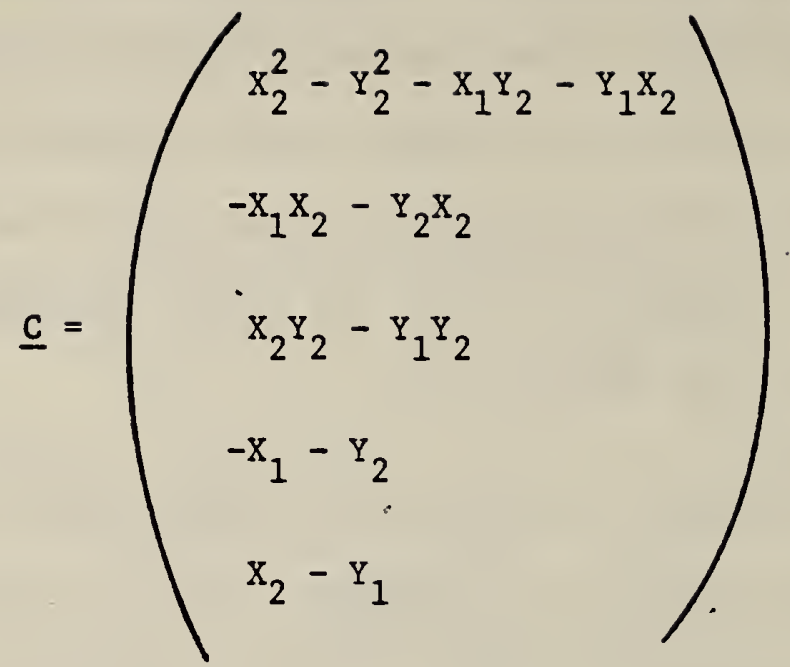

(18b)

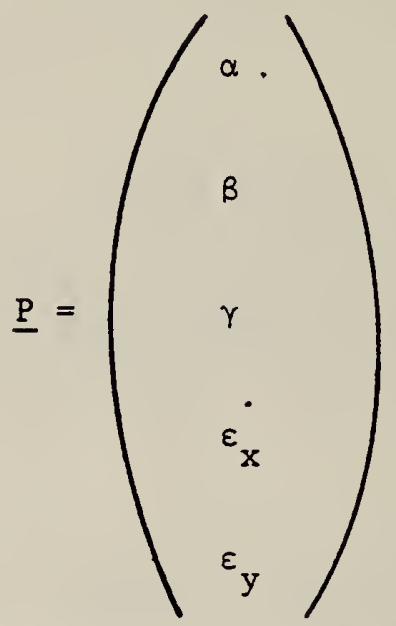

$(18 c)$

The solution to equation (17) may be obtained by inversion of the matrix $\underline{\underline{D}}$, or, because of the low order of the matrix, by Kramer's rule. The latter method is that used in the computer programs given in the appendices.

Let us now suppose we have obtained the solution to equation (17), i.e., we have the best fit values of $\alpha, \beta, \gamma, \varepsilon_{\mathbf{x}}$ and $\varepsilon_{\mathrm{y}}$ as well as the 
value for chi-squared. Using these parameters we can calculate a value for the "true" coordinates. The equations are:

$$
\underline{x}_{1}=\stackrel{A}{=}^{-1} X_{1 i}^{\prime}
$$

and

$$
\underline{X}_{1}=\underline{B}^{-1} \cdot \underline{A}^{-1} \underline{X}_{21}^{\prime}+\underline{\varepsilon}
$$

A resulting "best" value for the coordinates may be obtained by a simple average; that is:

$$
\underline{\bar{X}}_{i}=\frac{1}{2}\left(\underline{\underline{A}}^{-1} \mathrm{X}_{1 i}^{\prime}+\underline{\underline{B}}^{-1} \underline{A}^{-1} \underline{x}_{2 i}^{\prime}\right)
$$

where we have already subtracted a factor $\frac{1}{2} \underline{\varepsilon}$ in order that the reference point have coordinates $(0,0) .^{\dagger}$ In this calculation of the best values for the coordinates the result is no longer independent of the choice of $\stackrel{A}{=}$, unless $\gamma$ is zero. Here the metrologist must decide which of the three forms to use and this decision can only be based upon prior information or intuition. (The computer program given in the appendices has the option for using any of the three forms.) The set of coordinates, $\underline{x}_{i}$, are.still probably not in the desired system as they are in a coordinate system aligned with the machine axes. They are put into the preferred gage system, which usually has one point with a large $X$ coordinate which is specified to have a zero $Y$ coordinate, by a simple rotation. If cale was taken in the initial alignment this rotation will be small, but this is not a

tSince the vector $\underline{\varepsilon}$ does not appear in the final solution for the coordinates its introduction may be unnecessary. This, however, would be difficult to prove as the coefficients for $\varepsilon_{\mathrm{x}}$ and $\underline{\varepsilon}_{\mathrm{y}}$ do appear in the solutions for the other parameters 
necessity for the algorithm to work. All that is required is that positions 1 and 2 differ by a rotation that is within about $10 \mathrm{sec}$ of $90^{\circ}$.

\section{RESULTS}

This algorithm was checked in two different ways. The first check consisted of trying the program on data which was computer generated. This data is shown in Table 1 which includes the "true" values, the two sets of coordinates as seen in two positions nearly 90 degrees apart fitting the data (using option 3, i.e., splitting the metric error). The slight disagreements between the computed coordinates and parameters and the "true" values are interpreted. as stemming from the truncation of the data at the microinch level. Also shown are the results of Reeve's program applied to the same data.

Some testing of this algorithm has also been done on real data obtained from the NBS 2-D ball plate measured on our Moore 5-Z coordinate measuring machine. If the scale error $(\gamma)$ is set equal to zero the values obtained agree well with those obtained from using the full multiple redundancy of Reeve. These numbers are presented in Table 2.

\section{CONCLUSIONS}

It appears that this algorithm can be a valuable and relatively simple tool for uncovering and correcting for simple errors in machine geometry. Its advantages when compared with the complete multiple redundancy of Reeve are three-fold. First, it is simple enough to be programmed on a small computer, if the machine has the capability of double precision 
ar1thmetic.* Secondly, this algorithm includes a provision for assessing scale errors and, thirdly, the measurement method required coincides with techniques usually used by the operators of measuring machines. On the negative side, this method is definitely less flexible in terms of what kinds of measurements it requires; the desire to keep the program small enough for a minicomputer leads to necessarily stringent requirements on alignment to keep our approximations valid. Also, this method requires fewer measurements than the original algorithms which may prevent the averaging of other errors that is inherent in full multiple redundancy and the statistics used are certainly of an ad hoc nature. The fact that it gives the same answers and standard deviations as the more powerful method assures us somewhat on this latter point.

In order to make this technique more useful to a variety of measuring machine users, a program using the simple metric, equation (2), and a program with the option of choosing one or all of the other three, are provided in the appendices. They are in double precision Fortran of a vintage suitable for most compilers. The program for the metric described in the text is in Appendix D, while Appendix C contains a program for a simpler metric and Appendix B the proof that the observational equations are the same for any of the three matrices, equations ( 3$),(4)$, and (5).

*Least square fitting of this type requires taking differences of very large numbers which are often very similar in value. In coordinate measurement so many significant figures are required and differences are so small, it is doubtful that any of the programs described would work in single precision. 
Table 1. Results of Programs Applied to Computer-generated Data.

\begin{tabular}{|c|c|c|c|c|c|}
\hline & \multirow[b]{2}{*}{ True Values } & \multicolumn{2}{|c|}{ Raw Data } & \multirow{2}{*}{$\begin{array}{l}\text { ALBE } 3 \\
\text { Results } \\
\text { Option } 3\end{array}$} & \multirow{2}{*}{$\begin{array}{l}\text { Reeve } \\
\text { Results }\end{array}$} \\
\hline & & Position 1 & Position 2 & & \\
\hline$\overline{x_{1}}$ & .000000 & .000000 & .000010 & .000000 & .000000 \\
\hline$x_{2}$ & 12.526471 & 12.526643 & .001604 & 12.526471 & 12.526557 \\
\hline$x_{3}$ & 3.141597 & 3.141647 & 2.674759 & 3.141597 & 3.141619 \\
\hline$x_{4}$ & .132671 & .132702 & 11.989814 & .132671 & .132674 \\
\hline$x_{5}$ & 12.026450 & 12.026648 & 13.779498 & 12.026449 & 12.026532 \\
\hline$x_{6}$ & 6.936245 & 6.936358 & 7.217926 & 6.936245 & 6.936293 \\
\hline$x_{7}$ & 12.137425 & 12.137615 & 9.875151 & 12.137425 & 12.137508 \\
\hline $\mathrm{x}_{8}$ & 1.110020 & 1.111044 & 3.762727 & 1.110020 & 1.110028 \\
\hline$x_{9}$ & 9.735164 & 9.735305 & 3.166073 & 9.735164 & 9.735231 \\
\hline $\mathrm{Y}_{1}$ & .000000 & .000000 & -.000014 & .000000 & .000000 \\
\hline$Y_{2}$ & .000000 & -.000091 & -12.526485 & -.000000 & -.000000 \\
\hline$Y_{3}$ & 2.674327 & 2.674304 & -3.141279 & 2.674327 & 2.674346 \\
\hline$Y_{4}$ & 11.989642 & 11.989641 & -.131198 & 11.989642 & 11.989724 \\
\hline$Y_{5}$ & 13.777777 & 13.777683 & -12.024755 & 13.777770 & 13.777864 \\
\hline$Y_{6}$ & 7.216943 & 7.216893 & -6.935364 & 7.216943 & 7.216993 \\
\hline$Y_{7}$ & 9.873462 & 9.873374 & -12.136215 & 9.873462 & 9.873530 \\
\hline$Y_{8}$ & 3.762542 & 3.762534 & -1.110568 & 3.762542 & 3.762568 \\
\hline $\mathrm{Y}_{9}$ & 3.164785 & 3.164715 & -9.734786 & 3.164786 & 3.164807 \\
\hline \multicolumn{6}{|c|}{ Parameters $\left(\mathrm{X}_{1} 0^{-6}\right)$} \\
\hline Alpha & 4.79 & -- & -- & 4.81 & 4.66 \\
\hline Beta & -131.26 & -- & - & -131.24 & -133.98 \\
\hline Gamma & 13.70 & - & -- & 13.69 & -- \\
\hline$x$-offset & -14.20 & -- & -- & $\cdot-14.04$ & -13.67 \\
\hline$Y$-offset & 9.60 & - & - & 9.45 & 10.01 \\
\hline Sigma & - & -- & -- & .5 & 57.5 \\
\hline
\end{tabular}

* All dimensions are in inches and angles are in radians. Gamma is dimensionless. 
Table 2. Results of Programs Applied to Real Data

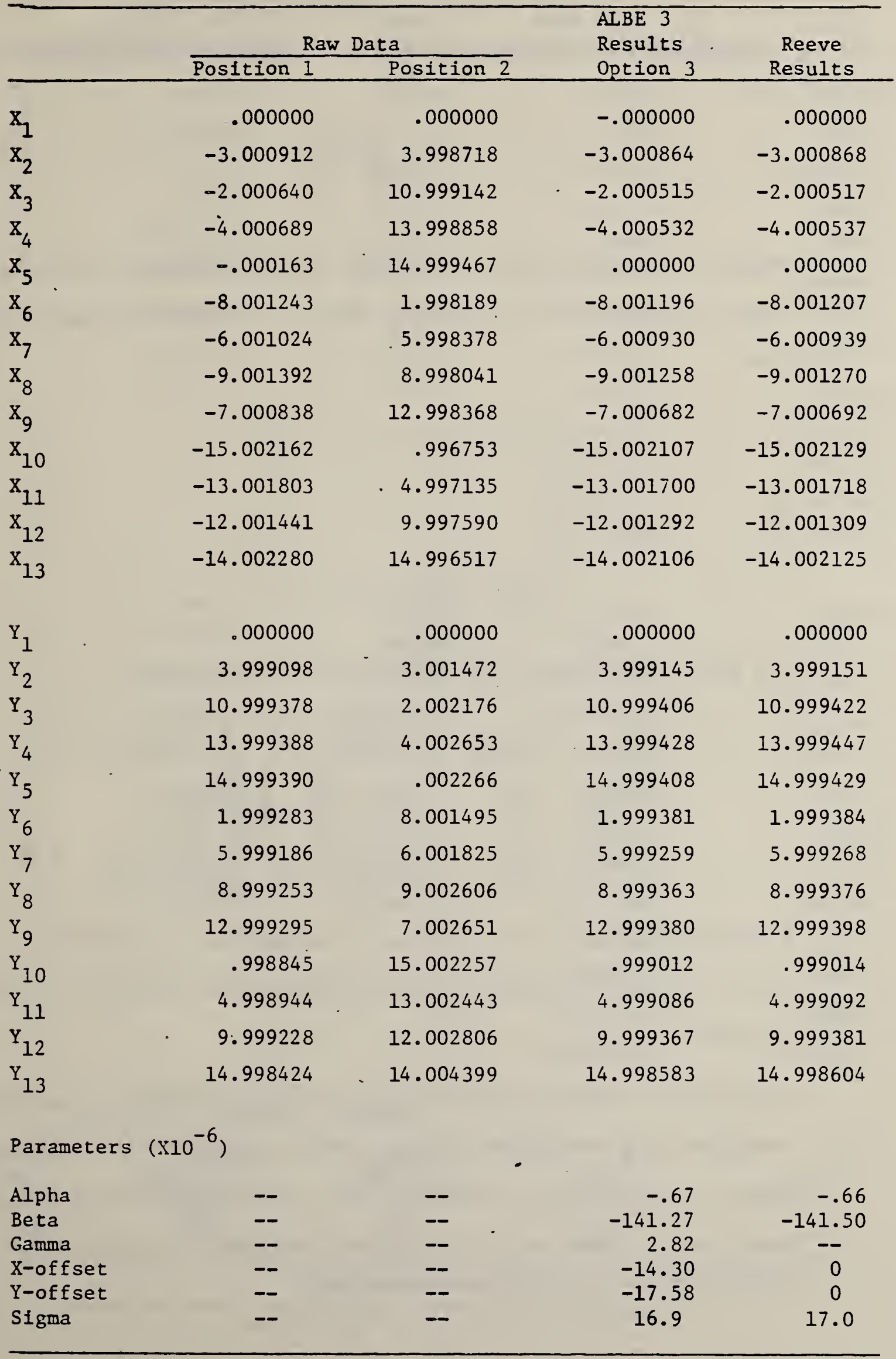


A simple form for the machine metric is that described in the text, that is

$$
\underline{\underline{A}}=\left(\begin{array}{lr}
1+\gamma-\alpha \\
0 & 1
\end{array}\right)
$$

This metric can be used and a simpler computation (with a shorter program) done by neglecting the offsets $\varepsilon_{x}$ and $\varepsilon_{y}$. The observational equations are then

$$
X_{1 i}^{\prime}=-(\beta+\alpha) x_{2 i}^{\prime}-(1+\gamma) Y_{2 i}^{\prime}
$$

and

$$
Y_{1 i}^{\prime}=(1-\gamma)+(\alpha-\beta) Y_{2 i}^{\prime}
$$

The linear equations at the minimum in chi-squared are:

$$
\left(\begin{array}{ccc}
0 & 2 \mathrm{X}_{2} \mathrm{Y}_{2} & \mathrm{Y}_{2}^{2}+\mathrm{X}_{2}^{2} \\
\mathrm{X}_{2}^{2} & \mathrm{X}_{2}^{2} & \mathrm{Y}_{2} \mathrm{X}_{2} \\
-\mathrm{Y}_{2}^{2} & \mathrm{Y}_{2}^{2} & \mathrm{Y}_{2} \mathrm{X}_{2}
\end{array}\right)\left(\begin{array}{l}
\alpha \\
\beta \\
\gamma
\end{array}\right)=\left(\begin{array}{l}
\mathrm{x}_{2}^{2}-\mathrm{Y}_{2}^{2}-\mathrm{X}_{1} \mathrm{Y}_{2}-\mathrm{Y}_{1} \mathrm{X}_{2} \\
-\mathrm{X}_{1} \mathrm{X}_{2} \\
\mathrm{X}_{2} \mathrm{Y}_{2}-\mathrm{Y}_{1} \mathrm{Y}_{2}
\end{array}\right)
$$

A Fortran program for the solution of $A 3$ appears as Appendix $C$.

Table Al shows the results of the program on the dummy data described in the text.

Table Al also shows the results on the real ball plate data previously described, and comparison of these results with those obtained using Reeve's full multiple redundancy. The large standard deviation in the Reeve result on the dumy data is due to the inclusion of a length scale error, $\gamma$, of $13.7 \mathrm{ppm}$ when the data were generated. 
Table Al. Results of Programs Applied to Computer-generated Data, with Offsets $E_{x}$ and $E_{y}$ Neglected.*

\begin{tabular}{|c|c|c|c|c|}
\hline & $\begin{array}{l}\text { ALBE } 2 \text { Results } \\
\text { on Dummy Data }\end{array}$ & $\begin{array}{c}\text { Reeve } \\
\text { Results } \\
\end{array}$ & $\begin{array}{c}\text { ALBE } 2 \text { Results } \\
\text { on Real Data }\end{array}$ & $\begin{array}{c}\text { Reeve } \\
\text { Results } \\
\end{array}$ \\
\hline$x_{1}$ & .000007 & .000000 & .000000 & .000000 \\
\hline $\mathrm{x}_{2}$ & 12.526483 & 12.526557 & -3.000862 & -3.000868 \\
\hline$x_{3}$ & 3.141604 & 3.141619 & -2.000514 & -2.000517 \\
\hline$x_{4}$ & .132673 & .132672 & -4.000530 & -4.000537 \\
\hline$x_{5}$ & 12.026455 & 12.026532 & -.000000 & .000000 \\
\hline$x_{6}$ & 6.936251 & 6.936293 & -8.001193 & -8.001207 \\
\hline$x_{7}$ & 12.137433 & 12.137508 & -6.000928 & -6.000939 \\
\hline$x_{8}$ & 1.111026 & 1.111028 & -9.001253 & -9.001270 \\
\hline$x_{9}$ & 9.735171 & 9.735231 & -7.000678 & -7.000692 \\
\hline$x_{10}$ & & & -15.002101 & -15.002129 \\
\hline$x_{11}$ & & & -13.001694 & -13.001718 \\
\hline$x_{12}$ & & - & -12.001287 & -12.001309 \\
\hline$x_{13}$ & & & -14.002099 & -14.002125 \\
\hline $\mathrm{Y}_{1}$ & -.000005 & .000000 & .000000 & .000000 \\
\hline $\mathrm{Y}_{2}$ & -.000000 & -.000000 & 3.999144 & 3.999151 \\
\hline$Y_{3}$ & 2.674324 & 2.674346 & 10.999401 & 10.999422 \\
\hline$Y_{4}$ & 11.989642 & 11.989724 & 13.999422 & 13.999447 \\
\hline$Y_{5}$ & 13.777775 & 13.777864 & 14.999401 & 14.999429 \\
\hline$Y_{6}$ & 7.216943 & 7.216993 & 1.999381 & 1.999384 \\
\hline $\mathrm{Y}_{7}$ & 9.873466 & 9.873530 & 5.999257 & 5.999268 \\
\hline$Y_{8}$ & 3.762539 & 3.762568 & 8.999460 & 8.999376 \\
\hline$Y_{9}$ & 3.164785 & 3.164807 & 12.999374 & 12.999398 \\
\hline$Y_{10}$ & & & .999012 & 999014 \\
\hline$Y_{11}$ & & & 4.999084 & 4.999092 \\
\hline $\mathrm{Y}_{12}$ & & & 9.999362 & 9.999381 \\
\hline$Y_{13}$ & & & 14.998577 & 14.998604 \\
\hline
\end{tabular}

Parameters $\left(10^{-6}\right.$ inches or radiams)

\begin{tabular}{|c|c|c|c|c|}
\hline Alpha & 5.03 & 4.66 & -.81 & -.66 \\
\hline Beta & -130.55 & -133.98 & -140.40 & -141.50 \\
\hline Gamma & $12: 99$ & - & 3.69 & - \\
\hline Sigma & 7.0 & 57.5 & 17.6 & 17.0 \\
\hline
\end{tabular}

*All dimensions are in inches and angles are in radians. 


\section{Appendix B}

EQUIVALENCE OF THE OBSERVATIONAL EQUATIONS FOR THE THREE FORMS OF METRIC ERROR.

Three logical choices for a machine, metric with scale errors were given in the text. They were

$$
\begin{aligned}
& \stackrel{\mathrm{A}_{\mathrm{x}}}{=}\left(\begin{array}{cc}
1+\gamma & -\alpha \\
0 & 1
\end{array}\right) \\
& \stackrel{\mathrm{A}}{\Rightarrow}=\left(\begin{array}{cc}
1 & -\alpha \\
0 & 1-\gamma
\end{array}\right)
\end{aligned}
$$

and

$$
\underline{\underline{A}}=\left(\begin{array}{rr}
1+\frac{\gamma}{2} & ,-\alpha \\
0 & 1-\frac{\gamma}{2}
\end{array}\right)
$$

The basic observational equation is, in matrix notation,

$$
\underline{X}_{1 i}^{\prime}=\underline{\underline{A}} \underline{B}^{-1} \underline{\underline{A}}^{-1} X_{2 i}^{\prime}+\underline{\varepsilon}=\underline{\underline{C}} \underline{X}_{2 i}^{\prime}+\underline{\varepsilon}
$$

To show that the three metrics above yield the same observational equations we need only to show that

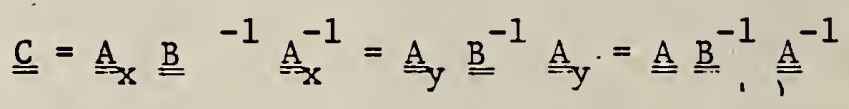

For the case where the metric is given by $\frac{A}{x}$ we have already shown in the text that

$$
\underline{\underline{C}}=\left(\begin{array}{cc}
-(\beta+\alpha) & -(1+\gamma) \\
(1-\gamma) & \alpha-\beta
\end{array}\right)
$$

when

$$
\underline{\underline{B}}^{-1}=\left(\begin{array}{cc}
-\beta & -1 \\
1 & -\beta
\end{array}\right)
$$


The inverse forms for $\stackrel{A}{\Rightarrow}$ and $\underline{\underline{A}}$ are

$$
\stackrel{A}{y}^{-1}=\left(\begin{array}{ll}
1 & \alpha \\
0 & 1+\gamma
\end{array}\right)
$$

and

$$
\underline{\underline{A}}^{-1}=\left(\begin{array}{cc}
1-\gamma / 2 & \alpha \\
0 & 1+\gamma / 2
\end{array}\right)
$$

Substitution of either (B5a) or (B5b) into (B3) will yield, to first order in the parameters, $\underline{\underline{C}}$, as given in equation (B4). 
Appendix C

SJOR̃CLT:ISE ALEE?(X,Y,U,SIGVA,VPTG)

$c$

C X APID Y $\triangle K E$ THE ARRAYS FOH THE EATA. THE FIFET SILSCFIPT IP. ELCH

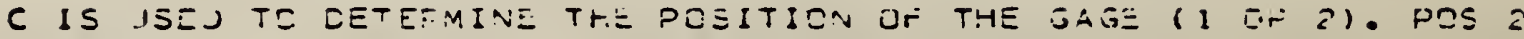

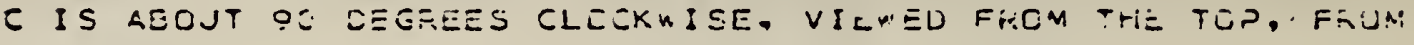

C PESITICN 1 .

C G(1)=NONOHTHCGUNALITY ANGLE. IN FIAJIANS

C $G(2)=K C T A T I C A$ DIFFERENCE FFOA S: JEGREES, RAUIAIUS

C $\quad O(3)=M E T K I C$ ERKOF (ASSUMEJ EUJAL EETWEEN $X$ IND $Y$ )

C SIGMATFIAS STANCAMD DEVIATICN IN CLONDINATËJ. JHITS 2ME THE SANE

$C$ AS THCSE 'USEU IN $X$ ANJ Y, NULTIPLIEL EY IECA.

c

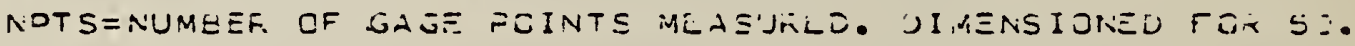

IMPLICIT DCUBLE DRECISICN $(A-H, O-Z)$

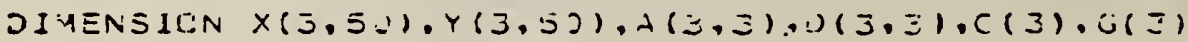

c

c

c

SET SUMS TE ZER̃C

$Y 25=\varepsilon .5 i$

$x \quad x=3.05$

$X Y 12=0.00$

$X Y 21=0.21$

$x Y \geq 2=\therefore . D 2$

$X \times 12=0.02$

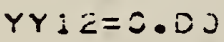

JO $100 \quad I=1$, NAPTS

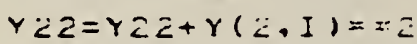

$x=2=x 22-\lambda(2, I) \neq x=2$

$\left.X Y: \bar{z}=X^{2} i 2+X(1,1)=Y, Z, 1\right)$

$X Y Z 1=X Y Z 1+X(Z, I)=Y(1, I)$

$X Y Z Z=X Y \leq Z+X(Z, I)=Y(Z, I)$

$X X 12=\lambda \lambda 12+X(1, I)+X(2, I)$

$1: j \quad Y Y ! \equiv=Y Y 12+Y(i, I) \times Y(Z, I)$

$c$

C SET UF MATRIX

c

$A(1,1)=$ E. こ

$\Delta(1,2)=2.06 * x Y 2 Z$

$A(1, z)=Y \angle Z+X<Z 2$

$A(2, i)=x 22$

$A(Z, \bar{Z})=x<2$

$\dot{A}(2,3)=x y 22$

$A(J, 1)=-Y\{.2$

$A(3, \geq)=Y=2$

$A(3, \Xi)=X Y Z 2$

$C(1)=-(\lambda Y i z+x Y Z 1+y \equiv z-x .2 z)$

$C(2)=-\lambda x i \Sigma-X Y Z 2$

$E(3)=-Y Y 1 Z+X Y Z Z$

c

C CJ CALCULATEE UETEKNIAANT DF A

C

$D D=D Z(A)$

C IF MATFIX IS DIRULLAR, JAIAT MESEAUE

IF( $20 . E: \therefore . J-) \quad \therefore F I^{\top}=(5.2-1)$

गO $15 \supset 1=1 . \ddot{0}$

כ0 $120 \quad 7=1.2$

DC $12 ? h=1.3$ 


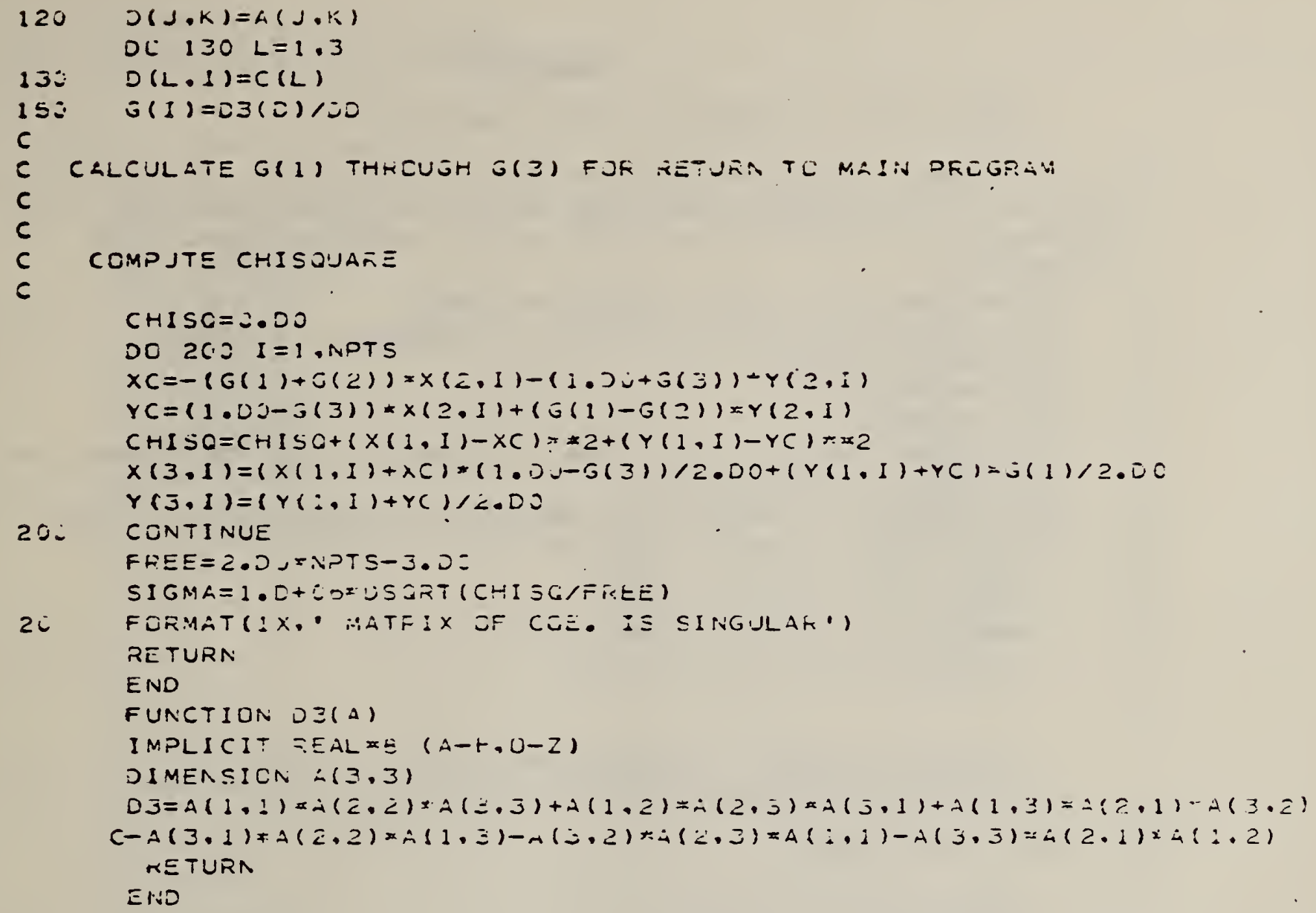


Appendix D

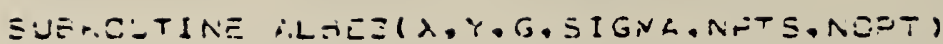

$c$

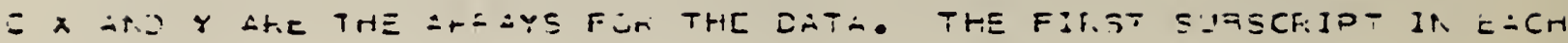

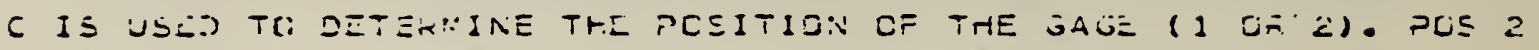

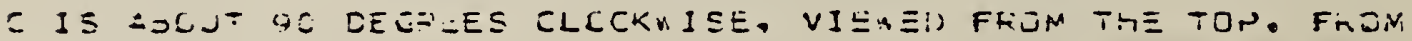

C PESITIUN 1

C S(1)=NENLRTHCUURALITY ANGLE. FILIANS

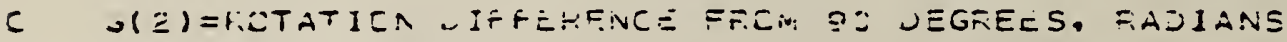

$=\quad$ S(Z)=RETIRIE ERIFIOR

C $G(4)=X-O F F \Xi \Xi \div$

$=\quad \Xi(\equiv 1=Y-C F F S=T$

$c$

$c$

ISMA=RMS ST IVLAE

LS THCSE USED IN $X$ : NU $Y$

WOTS=NUMEEF CF UALE PUINTS RIEASURED. DIMENSIUNED FCF $5: 0$

NOTT=CPTIZN TL CHCCSE FHRM LF उこALE EFFり2:

$1=\therefore L L$ ET-MF IS IN X $4 \times 1 S$

I=ALL EF KLF. IS IN.Y $L X \perp S$

3=EFFIUTR IS BPL $1 T$ BZTAEFIN $X$ ANJ Y AXIS

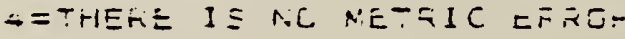

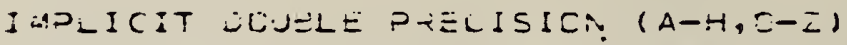

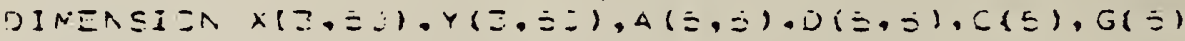

$\tau$

c

SET SLA:S - Z ZER.

DN=NPTS

$1 F(N C P T-Z)=3.01, U 2$

=: $\cdot$ วPT $=1 \cdot \Xi$ :

जU TU

$=1$ GPT=

GI TU 63

OPT =0・ = D?

COR.TINUE

$X 1=-. i J$

$Y 1=: \bullet \Sigma=$

$Y ?=-0.5$

$\mathrm{X} \angle=\mathrm{Y}=\mathrm{O}$;

Y..?=ン.D

$\times 22=? \cdot C \dot{Y}$

$X Y 12=0.03$

$X Y \hat{Z} i=2.0 ?$

$x y ? \Omega=\ldots .0 j$

XXI

YY\:=j.[i

$c$
$c$

วด โ נभ.

$3.1=\Omega \quad 1=1 \cdot n P^{-5}$

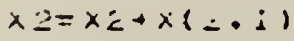

$Y 2=Y Z+Y(I, I)$

$X 1=X 1+X(1,1)$.

$Y l=Y 1+Y(1, I)$

$Y C Z=Y Z Z+Y(I, I)=\div$

$X Z Z=X E Z+X\left(\sum-i\right) \times 4$ ?

$X \times 1 z=X Y 1 Z+X ! 1, I)+Y(a, I)$

$Y Y Z 1=X Y Z 1+\lambda(Z, I)-Y(1,1)$

$X Y Z=X Y=Z+\lambda(Z, I)-Y(2.1)$ 


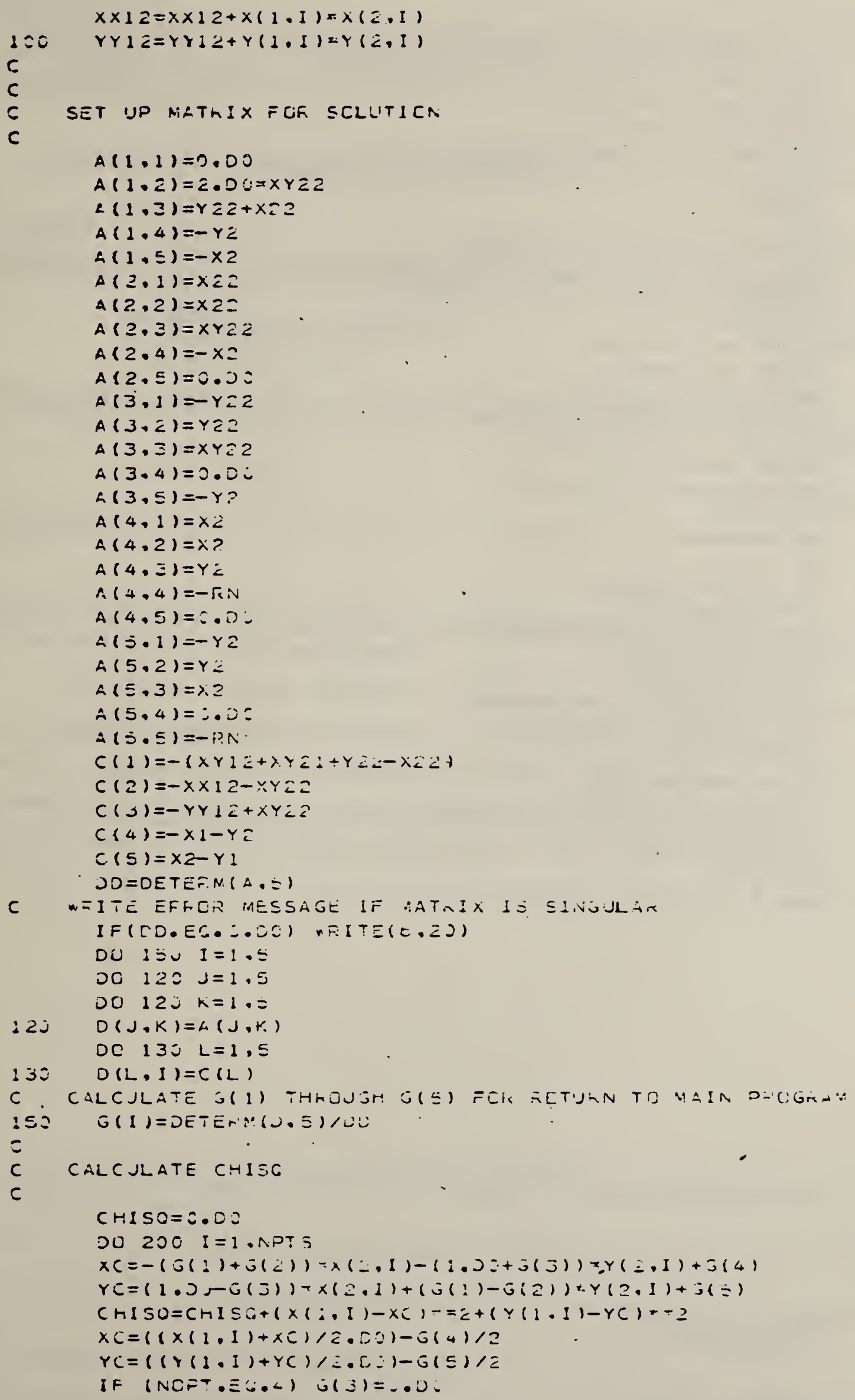




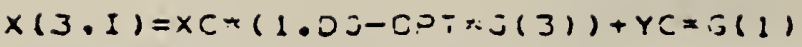

$Y(3,1)=(: . C Z+(1.0 E-C D T)=G(3)) \times Y C$

250 CUNTINUE

FF. $E L=2 . D J \pi$ JVTS $-5 . D:$

SIG:AA=1 D D U: ODSWRT (CHISL/FIREE)

$2 J$ FURMATIIX, HATRIX CF CCE. IS SINUULAT')

RETUTN:

END

FUNCTICW OETERN (AAA NCKDEF)

IMPLICIT COUALE DFECISICN (A-TI.G-Z)

DIMENSICN AREAY $(\equiv, D), A L(\equiv, S)$

10 DETERM= I.DO

DO $45 J=1$, ACRIOEF

DO $45 K=1$. NCGFUÉ

45 AKRAY $(J, K)=\angle A(J, K)$

11 DU $52 K=1$. NOFUEF

IF (AFPAY $(K, K)) 41,21,41$

21 DO $2 J J=K$. NEFTDEF

IF(AFRAY $(K, J)) \quad 31.23 .31$

23 CONTINUJE

DETERN=:-.UJ

GO TO E :

31 DO $341=K$. NEFDEF

SAVE=ARTIAY $(I, J)$

LFRLY $(I, J)=A F R A Y(I, K)$

34 ARFAY $(1, K)=S A V E$

DETERN =-OETERM

41 DETEKM=DETEFMYAFTAIY $\{r, K\}$

IF(K-nERUER) 4 E, $\leqslant ;, \equiv$,

$43 \quad K:=K+1$

Dï 4 I I $=K 1$. NCIDDEK

JC 40 J $J=K \perp \cdot N[F, J E F$

46

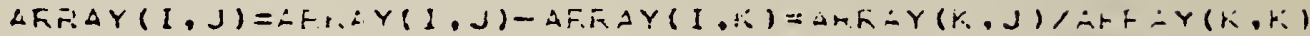

50 CDNTINUE.

65 RETURA

ENO 
NBS.II4A (REV. 7.73)

\begin{tabular}{|c|c|c|c|}
\hline $\begin{array}{l}\text { U.S. DEPT. OF COMM. } \\
\text { BIBLIOGRAPHIC DATA } \\
\text { SHEET }\end{array}$ & $\begin{array}{l}\text { 1. PUBLICATION OR REPORT NO. } \\
\text { NBSIR } 79=1752\end{array}$ & $\begin{array}{l}\text { 2. Gor't Accession } \\
\text { No. }\end{array}$ & 3. Recipient's Accession No. \\
\hline \multicolumn{3}{|l|}{ 4. TITLE AND SUBTITLE } & $\begin{array}{c}\text { 5. Publication Date } \\
\text { June } 1979 \\
\end{array}$ \\
\hline \multicolumn{3}{|c|}{ ON CHARACTERIZING MEASURING MACHINE GEOMETRY } & 6. Performing Organization Code \\
\hline \multicolumn{3}{|c|}{$\begin{array}{l}\text { 7. AUTHOR(S) } \\
\text { Robert J. Hocken and Bruce R. Borchardt }\end{array}$} & 8. Performing Organ. Report No. \\
\hline \multicolumn{3}{|c|}{$\begin{array}{l}\text { 9. PERFORMING ORGANIZATION NAME AND ADDRESS } \\
\text { NATIONAL BUREAU OF STANDARDS } \\
\text { DEPARTMENT OF COMMERCE } \\
\text { WASHINGTON, D.C. } 20234\end{array}$} & \begin{tabular}{|l|} 
10. Project/Task/Work Unit No. \\
7311124 \\
11. Contract/Grant No.
\end{tabular} \\
\hline \multirow{2}{*}{\multicolumn{3}{|c|}{ 12. Sponsoring Organization Name and Complete Address (Street, City, State, ZIP) }} & $\begin{array}{l}\text { 13. Type of Repors \& Period } \\
\text { Covered }\end{array}$ \\
\hline & & & 14. Sponsoring Agency Code \\
\hline
\end{tabular}

16. ABSTRACT (A 200-word or less factual summary of most significant information. If document includes a significant bibliography or literature survey, mention it here.)

We present a simple method for removing axis nonorthogonality and checking for length dependent scale errors in two-dimensional measurements. Use of this method requires that a two-dimensional master gage (ball or grid plate, for example) be measured in two positions wh ${ }^{3}$ differ by a rotation of the plate $90^{\circ}$ with respect to the measuring machine axes. The method is similar to that proposed by Reeve, but requires only linear least squares fitting on a small computer.

17. KEY WORDS (six to twelve entries; alphabetical order; capitalize only the first letter of the first key word unless a proper name; separated by semicolons)

Ball plate; grid plate; machine geometry; measuring machine; 3-D metrology; redundancy

18. AVAILABILITY E Unlimited

For Official Distribution. Do Not Release to NTIS

Order From Sup. of Doc., U.S. Government Printing Office Washington, D.C. 20402, SDC.Ae. No. C.I3

Order From National Technical Information Service (NTIS) Springfield, Virginia 22151

\begin{tabular}{|l|c|}
\hline $\begin{array}{l}\text { 19. SECURITY CL.ASS } \\
\text { (THIS REPURT) }\end{array}$ & 21. NO. OF P.AGES \\
UNCL ASSIFIED & 22 \\
\hline $\begin{array}{l}\text { 20. SECURITY CLASS } \\
\text { (THIS PAGE) }\end{array}$ & 22. Price \\
UNCLASSIFIED & $\$ 3.00$ \\
\hline
\end{tabular}




